\title{
Imaging Evaluation of Patients with Cranial Nerve Disorders
}

\author{
Alexandre Krainik and Jan W. Casselman
}

\section{Abbreviations}

$\begin{array}{ll}\text { ADC } & \text { Apparent diffusion coefficient } \\ \text { CN } & \text { Cranial nerves } \\ \text { CNS } & \text { Central nervous system } \\ \text { CT } & \text { Computed tomography } \\ \text { CTA } & \text { Computed tomography angiography } \\ \text { DWI } & \text { Diffusion weighted images } \\ \text { FS } & \text { Fat-saturated } \\ \text { MRA } & \text { Magnetic resonance angiography } \\ \text { MRI } & \text { Magnetic resonance imaging } \\ \text { MS } & \text { Multiple sclerosis } \\ \text { NF } & \text { Neurofibromatosis } \\ \text { NMOsd } & \text { Neuromyelitis optica spectrum disorders } \\ \text { NVC } & \text { Neurovascular conflict } \\ \text { SWI } & \text { Susceptibility weighted images } \\ \text { TOF } & \text { Time of flight } \\ \text { TZ } & \text { Transition zone } \\ \text { WI } & \text { Weighted images }\end{array}$

\section{Learning Objectives}

- To know the imaging appearance of the most frequent cranial nerve lesions and be aware of associated $\mathrm{CN}$ disorders

- To understand that different lesions can be found on the different anatomical segments of the cranial nerves (intraaxial, extraaxial intracranial, extracranial) and that dedicated imaging techniques are needed to investigate these different segments and various pathologies

\section{A. Krainik $(\bowtie)$}

Department of Neuroradiology, University Hospital of Grenoble, Grenoble, France

J. W. Casselman

AZ Sint-Jan Brugge-Oostende AV, Brugge, Belgium

\section{Key Points}

- Intraaxial lesions usually cause multiple $\mathrm{CN}$ disorders in association with CNS dysfunctions

- Extraaxial intracranial lesions may cause unique or multiple $\mathrm{CN}$ disorders with meningeal syndrome and intracranial hypertension

- Skull base lesions usually cause unilateral unique or multiple $\mathrm{CN}$ disorders.

- Extracranial lesions may cause unilateral unique or multiple $\mathrm{CN}$ disorders with craniocervical objective lesions.

- Painful CN disorder may reveal aneurysm and dissection

\section{Key Points}

- Be aware of clinical history, presentation, and biological tests for imaging interpretation

- Master CN anatomy including nucleus, apparent origin, route, and target

- MRI is the modality of choice to investigate $\mathrm{CN}$ disorder

- CT is useful to depict calcification and skull lesion

- Add MRA and CTA when painful CN disorder

\subsection{Introduction}

Cranial nerves $(\mathrm{CN})$ are 12 pairs of symmetrical nerves that apparently originate from the cerebrum (I, II) and the brainstem (III-XII). Beyond this regional common thread, $\mathrm{CN}$ imaging encompasses complex anatomical and technical considerations that need to be known for clinical practice.

$\mathrm{CN}$ disorders are caused by a wide spectrum of diseases and imaging plays a major role in the etiological inquiry and 
the therapeutic planning. Guided by medical history and clinical examination, and completed by neurophysiological and biological tests, radiologists have to select the appropriate modalities, to adapt the spatial coverage, and to choose the most relevant protocol.

$\mathrm{CN}$ imaging has to demonstrate the location of the disease: into the brain (intraaxial), out of the brain and into the skull (extraaxial intracranial), out of the skull (extracranial). According to the location, $\mathrm{CN}$ imaging allows to suggest pathophysiological hypotheses and etiologies including vascular, inflammatory, infectious, tumoral, traumatic, or dysfunctional disorders.
This chapter briefly reviews most common diseases that cause $\mathrm{CN}$ disorders. Additional details can be found in [1-8].

\subsection{Anatomical and Technical Challenges}

\subsubsection{Anatomical Challenge}

The $\mathrm{CN}$ anatomy is complex regarding their number, brain nuclei and connections, apparent origins, cisternal and foraminal courses, end organs. Mastering the $\mathrm{CN}$ anatomy and function is necessary to investigate $\mathrm{CN}$ disorders appropriately (Table 12.1).

Table 12.1 Cranial nerves disorders and apparent routes

\begin{tabular}{|c|c|c|c|c|}
\hline $\mathrm{CN}$ name & Main dysfunctions & CNS coverage & Skull base coverage & Face and neck coverage \\
\hline I: Olfactory & Anosmia & $\begin{array}{l}\text { Basal forebrain: olfactory } \\
\text { tracts, bulbs, and striae. Uncus, } \\
\text { parahippocampal and cingular } \\
\text { gyri }\end{array}$ & $\begin{array}{l}\text { Anterior skull base: } \\
\text { cribriform plate }\end{array}$ & Nasal mucosa \\
\hline II: Optic & $\begin{array}{l}\text { Vision loss } \\
\text { Prechiasmatic: onilateral } \\
\text { anopia } \\
\text { Chiasmatic: bitemporal } \\
\text { hemianopia } \\
\text { Retrochiasmatic: } \\
\text { homonymous hemianopia }\end{array}$ & $\begin{array}{l}\text { Basal forebrain: optic } \\
\text { radiation, chiasma, lateral } \\
\text { geniculate bodies, occipital } \\
\text { calcarine sulci }\end{array}$ & $\begin{array}{l}\text { Anterior skull base: } \\
\text { optic canal }\end{array}$ & Orbit: eye ball retina \\
\hline III: Oculomotor & $\begin{array}{l}\text { Oculomotor palsy, ptosis, } \\
\text { mydriasis }\end{array}$ & $\begin{array}{l}\text { Midbrain: interpedoncular } \\
\text { fossa }\end{array}$ & $\begin{array}{l}\text { Middle skull base: } \\
\text { cavernous sinus, } \\
\text { superior orbital } \\
\text { fissure }\end{array}$ & $\begin{array}{l}\text { Orbit: oculomotor m. (superior, } \\
\text { medial, inferior recti, inferior } \\
\text { oblique), levator palpebrae m., } \\
\text { ciliary m. }\end{array}$ \\
\hline IV: Trochlear & Trochlear palsy & Midbrain: tectum & $\begin{array}{l}\text { Middle skull base: } \\
\text { cavernous sinus, } \\
\text { superior orbital } \\
\text { fissure }\end{array}$ & Orbit: trochlear m \\
\hline V: Trigeminal & $\begin{array}{l}\text { Facial anesthesia } \\
\text { Trigeminal neuralgia }\end{array}$ & Pons: anterolateral & $\begin{array}{l}\text { Middle skull base: } \\
\text { cavernous sinus; } \mathrm{V}_{1} \text { : } \\
\text { superior orbital } \\
\text { fissure } \\
\mathrm{V}_{2} \text { : f. rotundum } \\
\mathrm{V}_{3} \text { : f. ovale }\end{array}$ & $\begin{array}{l}\text { Face } \\
V_{1}: \text { forebrain } \\
V_{2}: \text { chick } \\
\left.V_{3}: \text { Jaw, sensory tongue ( } 2 / 3 \text { ant }\right)\end{array}$ \\
\hline VI: Abducens & Abducens palsy & Medullopontine s. (ant.) & $\begin{array}{l}\text { Middle skull base: } \\
\text { cavernous sinus, } \\
\text { superior orbital } \\
\text { fissure }\end{array}$ & Orbit: abducens m. \\
\hline VII: Facial & $\begin{array}{l}\text { Facial palsy. Hemifacial } \\
\text { spasm }\end{array}$ & Medullopontine s. (lat.) & $\begin{array}{l}\text { Posterior skull base: } \\
\text { internal auditory } \\
\text { canal, stylomastoid } \mathrm{f} \text {. }\end{array}$ & $\begin{array}{l}\text { Face m., lacrimal and salivary } \\
\text { glands }\end{array}$ \\
\hline $\begin{array}{l}\text { VIII: } \\
\text { Cochleovestibular }\end{array}$ & $\begin{array}{l}\text { Hearing loss, tinnitus, } \\
\text { dizziness }\end{array}$ & Medullopontine s. (lat.) & $\begin{array}{l}\text { Posterior skull base: } \\
\text { internal auditory } \\
\text { canal }\end{array}$ & $\begin{array}{l}\text { Inner ear: cochlea and semicircular } \\
\text { canals }\end{array}$ \\
\hline $\begin{array}{l}\text { IX: } \\
\text { Glossopharyngeal }\end{array}$ & $\begin{array}{l}\text { Ageusia, dysphagia, throat } \\
\text { anesthesia. } \\
\text { Glossopharyngeal } \\
\text { neuralgia }\end{array}$ & Medulla: retroolivary s. & $\begin{array}{l}\text { Posterior skull base: } \\
\text { jugular foramen }\end{array}$ & $\begin{array}{l}\text { Stylopharyngeus } m . ; \text { sensory tongue } \\
\text { (1/3 post) }\end{array}$ \\
\hline $\mathrm{X}$ : Vagus & Dysphagia, dysphonia & Medulla: retroolivary s. & $\begin{array}{l}\text { Posterior skull base: } \\
\text { jugular foramen }\end{array}$ & Pharyngeal m. \\
\hline XI: Accessory & $\begin{array}{l}\text { Impairment of head } \\
\text { rotation, scapula elevation }\end{array}$ & $\begin{array}{l}\text { Medulla: retroolivary s., lateral } \\
\text { cervical cord }\end{array}$ & $\begin{array}{l}\text { Posterior skull base: } \\
\text { jugular foramen }\end{array}$ & Sternocleidomastoid, trapezius m. \\
\hline XII: Hypoglossal & Palsy of the tongue & Medulla: preolivary s. & $\begin{array}{l}\text { Posterior skull base: } \\
\text { hypoglossal canal }\end{array}$ & Tongue muscles \\
\hline
\end{tabular}

$m$. muscle, s. sulcus, ant. anterior, lat. lateral, post posterior 
Olfactory (I) and optic (II) nerves have both an apparent origin from the basal forebrain, passing through the foramina of the anterior cranial fossa. Both olfactory and optic nerves are tracts of the central nervous system (CNS).

All other $\mathrm{CN}$ originate apparently from the brainstem: oculomotor (III) and trochlear (IV) nerves from the midbrain; trigeminal (V) from the pons; abducens (VI), facial (VII), and cochleovestibular (VIII) nerves from the medullopontine sulcus; glossopharyngeal (IX), vagus (X), accessory (XI), and hypoglossal (XIII) nerves from the medulla oblongata. CN III-VI merge into the cavernous sinuses and pass through the foramina of the middle cranial fossa. CN VIIXII pass through the foramina of the posterior cranial fossa.

Because of this anatomical distribution of the $\mathrm{CN}$ along the basal brain, the brainstem, and the skull base, there is a close relationship between the lesional location and the symptoms. Indeed, CN impairment depends on the location of the macroscopic lesion. When unique, distal extracranial lesions are associated with specific $\mathrm{CN}$ deficit while proximal intraaxial lesions may cause multiple $\mathrm{CN}$ impairment with additional central symptoms.

In clinical practice, imaging is used to explain $\mathrm{CN}$ impairments related to: (1) intraaxial lesions that compromise supranuclear connecting fibers, $\mathrm{CN}$ nuclei, and intramedullary fibers; (2) extraaxial intracranial lesions that compromise cisternal and intraforaminal CN fibers; (3) extracranial lesions that compromise facial and cervical portions of $\mathrm{CN}$.

Further anatomical and functional details can be found in textbooks [3-6].

\subsection{Technical Challenge}

\subsubsection{Conventional Imaging}

MRI is the best imaging modality to investigate $\mathrm{CN}$ disorders. However, computed tomography (CT) is useful to better visualize bone lesion, especially in case of trauma, inflammation (abscess) or in patients with compromised airways. CT still offers an immediate availability, a short acquisition time, and a non-magnetic environment.

Based first on the clinical data, MRI protocols have to be adjusted on $\mathrm{CN}$ regional anatomy by optimizing spatial coverage and selecting most appropriate sequences [2, 8]. Complementary contrast media injection has to be justified in accordance with the clinical presentation, lesional hypotheses, and initial imaging findings (Table 12.2).

The best way to detect cranial nerve pathology is to compare the size and signal intensity of the paired nerves. Due to the course of the cranial nerves this comparison is best achieved in the coronal plane for nerves I-VI and in the axial plane for nerves VII-XII. However, imaging in both axial and coronal planes decreases the chance to overlook pathology.
Frequently nerve enhancement is the only sign indicating cranial nerve involvement and therefore the use of gadolinium is recommended in most cases.

A phased array head coil is best suited to image all cranial nerves down to the level of the mandible but an additional neck coil is needed to visualize the lower cranial nerves in the neck and upper mediastinum (left CN X).

Pathology at the level of the $\mathrm{CN}$ nuclei and intramedullary fibers is best seen on selective proton density, T2-weighted, and multi-echo (m-FFE, Medic, Merge) images. 3D-FLAIR are more reliable than 2D because of better flow saturation. It decreases repetition artifacts and allow a better visualization of the brain stem. Post-contrast 3D-FLAIR is also useful to demonstrate abnormal meningeal and neural enhancements. Additional diffusionweighted images (DWI) are often needed to rule out stroke and to characterize tissular and cystic masses.

The cisternal segment of CN is surrounded by CSF and therefore submillimetric heavily T2-weighted images (WI) are best suited. All these sequences perform well in the center of the image and region around the brainstem and some of the steady state sequences can even cover all 12 cranial nerves. However, the steady state sequences (e.g., CISS, balanced-FFE, etc.) are prone to susceptibility artifacts at the level of the more peripheral located cisternal segments such as the olfactory bulbs and tracts, cranial nerve VII and VIII inside the internal auditory canal. Therefore these peripheral segments are better imaged with TSE sequences (e.g., DRIVE, 3D-TSE, etc.) that unfortunately have a smaller coverage.

Once the nerves are surrounded by a venous plexus (cavernous sinus, basilar plexus behind the clivus, jugular foramen, and hypoglossal canal) they are best depicted as black structures surrounded by high signal intensity enhancing venous structures on 2DSE or TSE, 3DTSE or FFE postcontrast T1-WI. The extracranial segments of the cranial nerves and surrounding lesions can best be depicted on highresolution axial and coronal $\mathrm{T} 1$ and $\mathrm{T} 2-\mathrm{WI}$.

Fat around the cranial nerves will disappear when fat saturation is used and renders visualization of the normal nerves more difficult. On the other hand abnormal enhancement of the nerves will be recognized more easily on fat-saturated images. The use of DIXON sequences avoids this sometimes difficult choice and provides both fat and non-fat-saturated (FS) images in one sequence.

New isotropic 3D unenhanced MR neurography sequences allow detailed visualization of the normal and abnormal extracranial branches and course of nerves V, VII, IX-XII. The sequences are based on a 3D TSE sequence with fat saturation and a motion sensitized driven equilibrium function (black blood function parallel to the nerves) [8]. To acquire all the above mentioned high-resolution images or isotropic submillimetric images in an acceptable 
Table 12.2 Technical recommendations to investigate $\mathrm{CN}$ disorders

\begin{tabular}{|c|c|c|c|c|}
\hline $\begin{array}{l}\mathrm{CN} \text { nuclei and } \\
\text { segments }\end{array}$ & $\begin{array}{l}\text { Brainstem: nuclei and } \\
\text { intramedullary fibers }\end{array}$ & Cisternal segment & $\begin{array}{l}\text { Segments surrounded by } \\
\text { venous plexus-intraforaminal } \\
\text { fibers }\end{array}$ & $\begin{array}{l}\text { Extracranial nerves-face, } \\
\text { neck, mediastinum }\end{array}$ \\
\hline Sequences & $\begin{array}{l}\text { T2-weighted/PD (2D) } \\
\text { DWI (2D) } \\
\text { m-FFE/medic/ } \\
\text { merge(2D)-nuclei }\end{array}$ & $\begin{array}{l}\text { b-FFE XD (3D) } \\
\text { DRIVE TSE T2 (3D) } \\
\text { MRA (3D) unenhanced }\end{array}$ & $\begin{array}{l}\text { T1-weighted TSE HR (2D) } \\
\text { FFE (3D) } \\
\text { Black blood TSE T1 (3D) }\end{array}$ & $\begin{array}{l}\text { T1-weighted TSE HR (2D) } \\
\text { T2-weighted TSE HR (2D) } \\
\text { Neurography (3D) }\end{array}$ \\
\hline Plane & Axial & $\begin{array}{l}\text { 3D sequences, isotropic. Measured } \\
\text { in the axial plane, reformatted in any } \\
\text { other plane }\end{array}$ & $\begin{array}{l}\text { Cavernous sinus: coronal } \\
\text { Basilar plexus: axial } \\
\text { Jugular foramen: } \\
\text { axial > coronal } \\
\text { Hypoglossal canal: } \\
\text { axial > coronal } \\
\text { 3D sequences: reformatted any } \\
\text { plane }\end{array}$ & $\begin{array}{l}\text { Axial + coronal } \\
\text { Neurography: axial 3D } \\
\text { isotropic }\end{array}$ \\
\hline $\begin{array}{l}\text { Resolution } \\
(X \times Y \times Z \text { in } \\
\mathrm{mm})\end{array}$ & $\begin{array}{l}\text { T2-weighted/PD: } \\
0.70 \times 0.88 \times 3.00 \\
\text { DWI: } \\
1.40 \times 1.42 \times 3.00 \\
\text { m-FFE: } \\
0.65 \times 0.87 \times 2.00\end{array}$ & $\begin{array}{l}\text { b-FFE XD: } 0.5 \times 0.5 \times 0.5 \mathrm{~mm} \\
\text { DRIVE T2: } 0.46 \times 0.46 \times 0.50 \mathrm{~mm} \\
\text { MRA: } 0.69 \times 0.70 \times 0.70 \mathrm{~mm}\end{array}$ & $\begin{array}{l}\text { T1-weighted TSE HR: } \\
0.40 \times 0.45 \times 2.30 \mathrm{~mm} \\
\text { FFE: } 0.60 \times 0.59 \times 1.20 \mathrm{~mm} \\
\text { Black blood: } \\
0.55 \times 0.55 \times 0.55 \mathrm{~mm}\end{array}$ & $\begin{array}{l}\text { T1-weighted TSE HR: } \\
0.40 \times 0.45 \times 2.3 \mathrm{~mm} \\
\text { T2-weighted TSE HR: } \\
0.60 \times 0.53 \times 3.3 \mathrm{~mm} \\
\text { Neurography: } \\
0.89 \times 0.90 \times 0.90 \mathrm{~mm}\end{array}$ \\
\hline Range & $\begin{array}{l}\text { T2-weighted/PD: } \\
60 \mathrm{~mm} \\
\text { DWI: } 128 \mathrm{~mm} \\
\text { m-FFE: } 48 \mathrm{~mm}\end{array}$ & $\begin{array}{l}\text { b-FFE XD: } 80 \mathrm{~mm} \\
\text { DRIVE T2: } 36 \mathrm{~mm} \\
\text { MRA: } 120 \mathrm{~mm}\end{array}$ & $\begin{array}{l}\text { T1-weighted TSE HR: } 69 \mathrm{~mm} \\
\text { FFE: } 59 \mathrm{~mm} \\
\text { Black blood: } 39 \mathrm{~mm}\end{array}$ & $\begin{array}{l}\text { T1-weighted TSE HR: } \\
69 \mathrm{~mm} \\
\text { T2-weighted TSE HR: } \\
106 \mathrm{~mm} \\
\text { Neurography: } 90 \mathrm{~mm}\end{array}$ \\
\hline $\begin{array}{l}\text { Acquisition } \\
\text { time }\end{array}$ & $\begin{array}{l}\text { T2-weighted/PD: } 2 \mathrm{~min} \\
31 \mathrm{~s} \\
\text { DWI: } 2 \min 21 \mathrm{~s} \\
\text { m-FFE: } 14 \min 46 \mathrm{~s}\end{array}$ & $\begin{array}{l}\text { b-FFE XD: } 4 \min 43 \mathrm{~s}(\mathrm{CS} 10) \\
\text { DRIVE T2: } 2 \min 47 \mathrm{~s}(\mathrm{CS} 3.3) \\
\text { MRA: } 6 \min 50 \mathrm{~s}(\mathrm{CS} 3)\end{array}$ & $\begin{array}{l}\text { T1-weighted TSE HR: } 7 \mathrm{~min} \\
30 \mathrm{~s}(\mathrm{~S} 1.5) \\
\text { FFE: } 4 \text { min } 8 \mathrm{~s}(\mathrm{~S} 1.4) \\
\text { Black blood: } 5 \text { min } 5 \mathrm{~s}(\mathrm{CS} 4)\end{array}$ & $\begin{array}{l}\text { T1-weighted TSE HR: } \\
7 \text { min } 30 \mathrm{~s} \text { (S 1.5) } \\
\text { T2-weighted TSE HR: } \\
3 \text { min } 15 \mathrm{~s}(\mathrm{CS} 2.5) \\
\text { Neurography: } 8 \text { min } 17 \mathrm{~s} \\
\text { (CS 3) }\end{array}$ \\
\hline
\end{tabular}

$2 D$ two dimensional, $3 D$ three dimensional, $b$ - FFE balanced fast field echo, $C N$ cranial nerve, $C S$ compressed sense factor, $D R I V E$ driven equilibrium, $D W I$ diffusion-weighted imaging, $F F E$ fast field echo, medic multi-echo data image combination, merge multiple echo recombine gradient echo, $m$ - $F F E$ merged fast field echo, $H R$ high resolution, $M R A$ magnetic resonance angiography, $P D$ proton density, $S$ sense factor, TSE turbo spin echo

time parallel imaging and if available compressed sense should be used.

\subsubsection{Tractography}

Advances in DWI clinical research have led to the development of cranial nerves tractographie based on diffusion tensor imaging. The visual results depend on the anatomy of the cranial nerve tracked, acquisition parameters, and the postprocessing steps. Currently, cranial nerves tractography techniques only allow to display the thicker nerves, including six isolated cranial nerves (II, III, V, VI, VII/VIII) and IX/X/XI nerves as a group [9] (Fig. 12.1).

The acquisition of high-angular resolution DWI data (at least 32 directions) is required to estimate the local fiber orientation distribution, a prior step to manage voxels with multiple fibers population. Such diffusion signal modeling is required, for example, when tracking nerves with secondary branches or in diseased condition. The other crucial point relies on the susceptibility distribution of the subjects' head, which needs to be corrected by specific postprocessing. It typically uses two b-zero acquisitions with opposing polarities of the phase-encode blips. In addition, the polarity of the diffusion directions has a major impact to pass through skull base foramina. For example, optic nerves tractography would require a postero-anterior acquisition to be feasible along the optic canal, while inner auditory canal nerves would take advantage of an antero-posterior MR acquisition.

It is well-known that probabilistic algorithms are the method of choice to track cranial nerves, including in tumor condition. Global tractographic reconstructions on the whole acquisition volume have also proved efficiency to map cranial nerves ischemia, for example, in anterior optic ischemic neuropathy [10]. Global tractographic approach also allows to obtain cranial nerves reconstructions at a submillimeter scale, regardless to the voxel size acquisition. Technical advances such as faster imaging acquisition and implementation of recent postprocessing developments in clinical software promise new perspectives in neuroradiology, skull base surgery, and neuroanatomy $[9,11,12]$. 

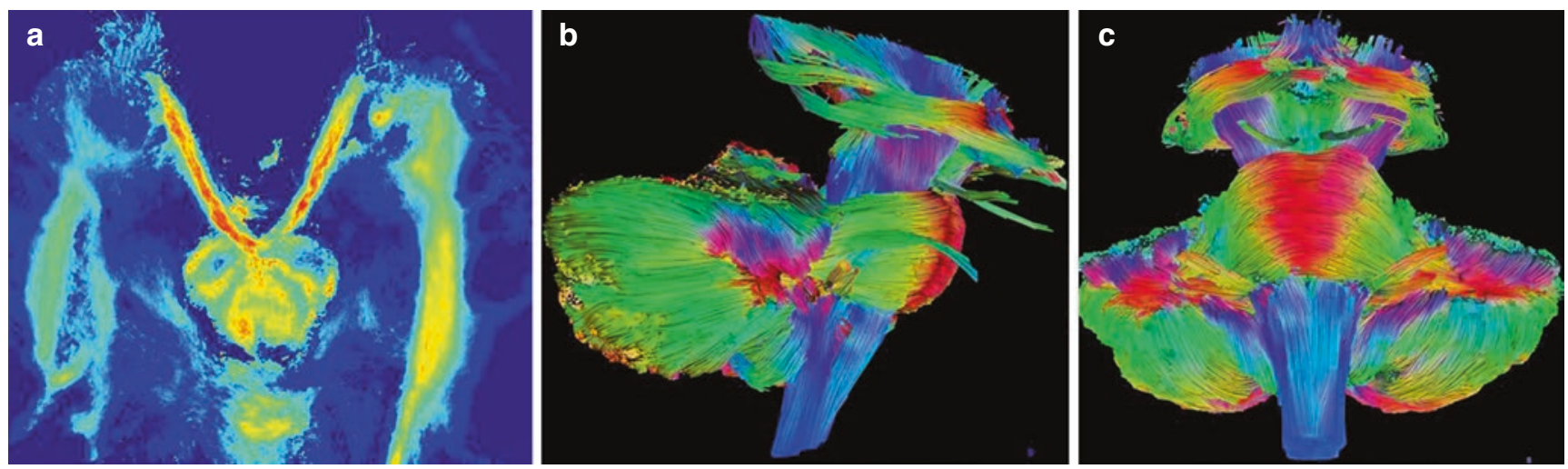

Fig. 12.1 Global tractography of the cranial nerves, brainstem, and cerebellum: (a) axial view of normal oculomotor nerves (III) arising from the interpeduncular fossa; $(\mathbf{b}, \mathbf{c}) 3 \mathrm{D}$ rendering in a healthy volun-

\subsection{Intraaxial Lesions}

Intraaxial lesions such as stroke, meningoencephalitis, central pontine myelinolysis, or glioma might have a spontaneous poor short-term prognosis without specific care. Then, identifying intraaxial lesion in case of $\mathrm{CN}$ impairment remains a diagnostic priority. Despite both olfactory (I) and optic (II) nerves are tracts of the CNS, their lesions are presented in their apparent location.

Because of the complex anatomy of the brainstem, intraaxial lesions are prone to be revealed by a rich clinical semiology, associating multiple $\mathrm{CN}$ impairment and central disorders such as hemiplegia, hemiparesia, extrapyramidal syndrome, dysautonomic syndrome, awareness impairment, nausea, cardiorespiratory dysregulation, etc. Recent imaging details are available in $[1,7]$.

\subsubsection{Vascular Diseases}

\subsubsection{Ischemic Stroke}

Stroke is the major cause of neurologic deficits with acute onset. Ischemic stroke is more frequent than hemorrhage. Except for acute ischemic optic neuropathy, $\mathrm{CN}$ disorders secondary to ischemic stroke is usually due to an occlusion of the basilar artery and its perforating arteries. Occlusion of the distal portion of the vertebral artery, the postero-inferior cerebellar artery and its branches is responsible of ischemia of the medulla. Intravenous thrombolysis is recommended within $4.5 \mathrm{~h}$ after onset. Recommendations for mechanical thrombectomy in the posterior circulation are under investigation, even after $6 \mathrm{~h}$.

Imaging in emergency is needed for brainstem stroke: (1) to distinguish ischemic from hemorrhagic stroke; (2) to estimate the duration of stroke in case of unclear history or awake stroke, (3) to identify intravascular thrombus, occlusion, and stenosis. teer. When compared to surgery, reliable tractography is obtained in most CN but IV and VI [9]

MRI is an excellent modality to demonstrate very acute infarction as a DWI hyperintensity due to a low apparent diffusion coefficient (ADC) (Fig. 12.2). T2 FLAIR hyperintensity reveals stroke after $4 \mathrm{~h}$. T2 $*$ or CT are helpful to rule out hemorrhage. CT angiography (CTA) or MR angiography (MRA) using time of flight (TOF) is useful to identify vascular occlusion or stenosis. Perfusion CT and MR are also useful to show penumbra, this reversible ischemia after reperfusion [13].

\subsubsection{Intraparenchymal Hemorrhage}

Spontaneous hemorrhage of the brainstem is usually due to vascular malformation, such as cavernoma. Arteriovenous malformation and fistula are less frequent. Cavernoma or cavernous hemangioma is a sporadic or familial vascular malformation, characterized by blood cavities due to dilated blood vessels. Abnormal structural support of the vessels may cause leakage and hemorrhage in the surrounding tissue. CT may show hyperdensities due to calcifications and hemorrhage. MRI may show a "pop-corn" like lesion with caverns of varied intensities. T2 may show a hypointense rim. Hemosiderin depositions are best seen using T2* and SWI. Post-contrast T1 images may show subtle enhancement and additional developmental venous anomaly.

\subsubsection{Infectious Diseases}

\subsubsection{Listeria}

Listerial rhombencephalitis is due to Listeria monocytogenes septicemia, which may occur in pregnancy, infant, elderly, and immunocompromised patients after oral contamination of infected fresh products such as cheese. Antiobiotherapy is required in emergency. MRI is the best modality to show pontine enlargement and T2 hyperintensities (Fig. 12.2). Perilesional enhancement might be associated with 

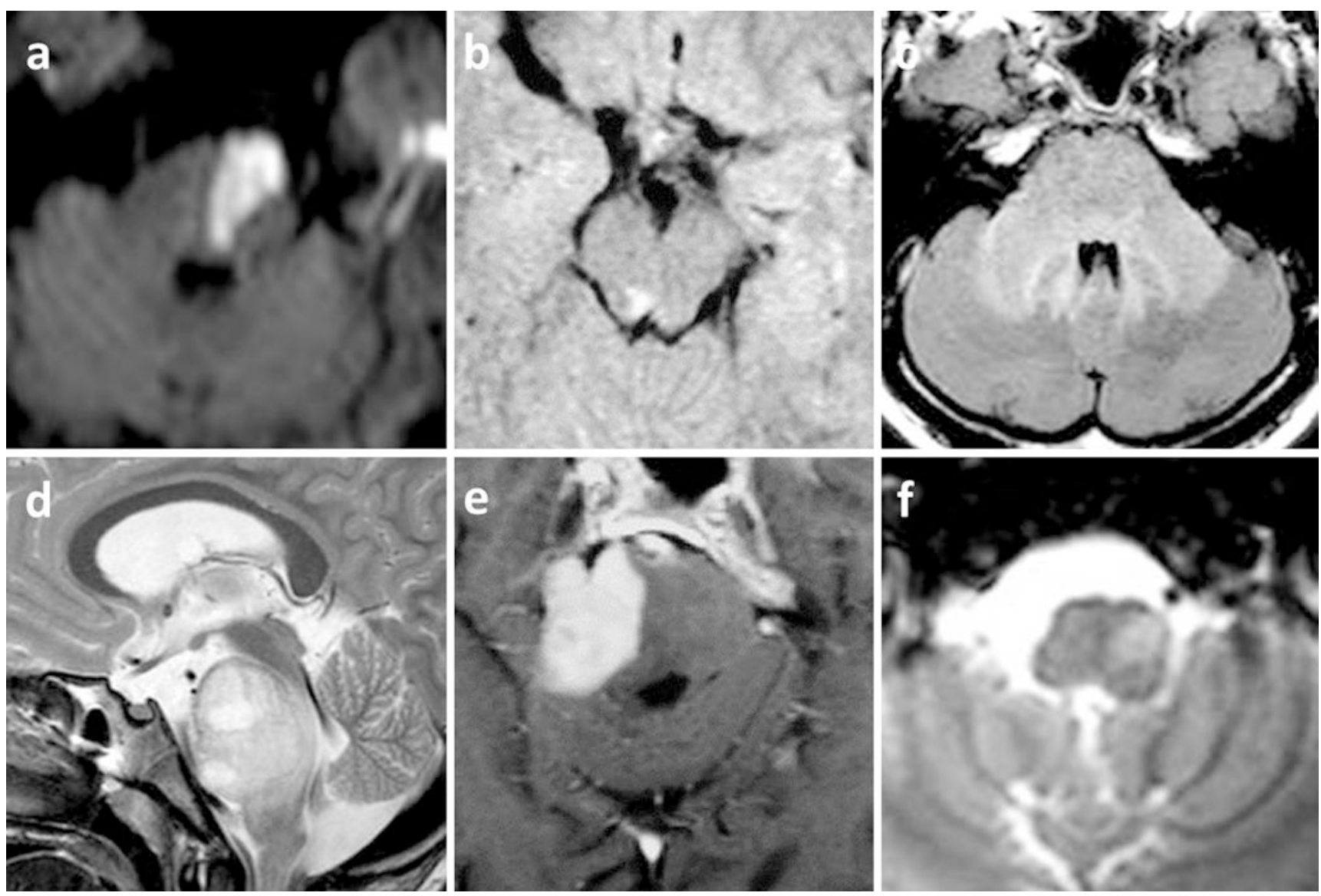

Fig. 12.2 Intraaxial lesions with $\mathrm{CN}$ disorders: (a) ischemic stroke of the left hemi-pons, DWI hyperintense pontine triangle, revealed by right hemiparesia and diplopia; (b) multiple sclerosis with a T2 hyperintense nodule close to $\mathrm{CN}$ III nucleus with a right oculomotor palsy and ptosis; (c) listerial rhombencephalitis as a T2 hyperintense infiltration of pons and cerebellar peduncles in a pregnant woman revealed by febrile confusion with bilateral oculomotor paresis; (d) midline diffuse glioma of the pons as aT2 hyperintense pontine mass, revealed by bilateral CN palsies (oculomotor and facial) and headaches; (e) primary CNS lymphoma, post-contrast T1 enhancing homogeneous right pontine mass, revealed by right trigeminal anesthesia and left hemiparesia; (f) left hypertrophic olivary degeneration (T2* hyperintensity) revealed by left palatal myoclonus, 6 months after ipsilateral mesencephalic cavernoma hemorrhage leptomeningeal and adjacent V4 ependymal enhancements. Foci of low ADC would have a poorer prognosis.

Any septicemia of different origins may also cause intraaxial abscesses.

\subsubsection{CMV}

Cytomegalovirus infection in immunocompromised patients may cause ventriculitis and encephalitis. MRI shows an ependymal enhancement with adjacent $\mathrm{T} 2$ hyperintense foci of inflammation that may insult $\mathrm{CN}$ nuclei and intraaxial fibers.

\subsubsection{Non-infectious Inflammatory Diseases}

\subsubsection{Demyelinating Diseases}

Demyelinating diseases is a heterogeneous group of inflammatory disorders, such as multiple sclerosis, neuromyelitis optica spectrum disorders (NMOsd) with anti-AQP4 or anti-
MOG antibodies, acute disseminated encephalomyelitis, etc. Clinical presentation and biological studies are helpful to discuss among diagnoses. Imaging of the brain and the spinal cord is also critical. All these diseases might be responsible of $\mathrm{CN}$ disorders due to nodular lesions involving the brainstem (Fig. 12.2). NMO with anti-AQP4 antibodies is often associated with periventricular and especially area postrema lesions $[14,15]$. Acute lesions may appear T2 hyperintense, DWI hyperintense due to low ADC within the first days after onset, and open ring perinodular enhancement during the first month. Optic neuritis may have suggestive presentations according to the diseases (see extracranial).

\subsubsection{Behcet's Disease}

Behcet's disease is a multisystem vascular-inflammatory disease of unknown origin that associates recurrent orogenital ulcerations, uveitis, and skin lesions. Males originating from countries along the Silk Road are more affected from 
Mediterranean to Far East. CNS involvement is rare but classical. Besides venous cerebral thrombosis, intraaxial illdefined lesions are often described in the pons, the midbrain, and the diencephalon. Irregular lesional contrast enhancement is possible.

\subsubsection{Tumor}

\subsubsection{Midline Infiltrating Glioma}

Midline infiltrating glioma is rare, usually diagnosed in children and young adults with a poor prognosis. The lesion typically arises in the pons or the thalamus. Rapidly progressive brainstem and cranial nerves disorders develop over few weeks in association with an obstructive hydrocephalus and intracranial hypertension. The lesion is a large expansive mass T1 hypointense, T2 hyperintense (Fig. 12.2). Although considered as a high grade glioma, intralesional necrosis and contrast enhancement are possible but unconstant. Spectroscopy demonstrates a malignant profile, with low NAA, high choline and choline/creatine ratio, and the presence of lactates and lipids.

\subsubsection{Other Intraaxial Tumors}

Other tumors that may infiltrate the brainstem are primary ependymoma, medulloblastoma, CNS lymphoma (Fig. 12.2), metastases. Tumoral hypercellularity appears as a DWI hyperintensity due to low ADC. This feature is common in medulloblastoma and lymphoma. Post-contrast enhancement is usually heterogeneous except in lymphoma which remains homogeneous in immunocompetent patients despite the large size of the tumor.

\subsubsection{Trauma}

\subsubsection{Diffuse Axonal Injuries and Contusions}

Severe traumatic brain injury is defined by Glasgow coma scale $<8$. In case of midbrain lesions, conscientiousness and awareness impairments are predominant. MRI may demonstrate diffuse axonal injuries due to structural neural shearing in case of high velocity trauma. These punctuate lesions, $\mathrm{T} 2 * /$ SWI hypointense, T2 hyperintense may also cause cranial nerve palsies and movements disorders. Additionally, CT and MRI may show post-traumatic contusion of the posterolateral aspect of the midbrain onto the tentorium as an edema and a superficial hemorrhage.

\subsubsection{Toxic/Metabolic}

\subsubsection{Central Pontine Myelinolysis}

Osmotic demyelination syndrome is usually observed after a rapid correction of electrolyte disturbance such as hypona- tremia. Central pontine myelinolysis is T2 hyperintense with a classical trident or piglet shape. Extrapontine myelinolysis may involve basal ganglia and deep white matter.

\subsubsection{Degeneration}

\subsubsection{Progressive Supranuclear Palsy}

Progressive supranuclear palsy is a neurodegenerative disease that is responsible of oculomotor disorders, especially with vertical gaze and convergence impairments. An extrapyramidal syndrome poorly responsive to L-Dopa administration is usually associated. On axial plane, the mesencephalic atrophy is responsible of a concavity of the posterior aspect of the midbrain, the "morning glory" sign. On mid-sagittal plane, the atrophy is responsible of the concavity of the superior aspect of the midbrain, the "hummingbird" sign.

\subsubsection{Hypertrophic Olivary Degeneration}

The hypertrophic olivary degeneration is secondary to a focal lesion, usually a hemorrhage or an ischemia involving the dento-rubro-olivary pathway. The olivary degeneration appears T2 hyperintense and hypertrophic several months after the initial injury (Fig. 12.2). When present, cerebellar changes, including superior cerebellar peduncles are contralateral to the olivary degeneration. Bilateral hypertrophic olivary degeneration is also possible.

\subsection{Extraaxial Intracranial Lesions}

Extraaxial intracranial lesions might insult the cisternal and the transdural portions of CN. These diseases include primary diseases of the nerves, secondary neural inflammation, and compression by vascular, meningeal, and skull bases diseases. $\mathrm{CN}$ disorders reveal the location and the extent of the lesions. Patient's history is critical for diagnosis. CN disorders can be unique or multiple. Additional symptoms such as pain may also suggest particular etiologies such as meningeal and neural inflammation, vascular disorders such as aneurysms and neurovascular conflicts. Headaches with nausea, vomiting, papillary edema, and abducens palsy suggest intracranial hypertension. When neuroimaging is normal, CSF study is needed. In clinical practice, CT is useful in emergency to rule out intracranial hypertension before lumbar puncture and for osseous skull study. MR is usually needed to refine the diagnosis [2, 8, 16-18].

\subsubsection{Vascular Diseases}

The close vicinity of $\mathrm{CN}$ and vessels explains why focal vascular diseases may cause $\mathrm{CN}$ disorders. 


\subsubsection{Aneurysm and Arterial Dissection}

First, life-threatening aneurysm and arterial dissection have to be ruled out in case of unilateral painful $\mathrm{CN}$. Aneurysms of the first portion of the posterior cerebral artery and the cerebral portion of the internal carotid artery may have a mass effect on the superior aspect of the oculomotor nerve (III), responsible of complete extrinsic and intrinsic oculomotor nerve palsy. Because preganglionic parasympathetic pupillomotor fibers to the ciliary ganglion are located on the superomedial surface of the CN III, the loss of pupillary function occurs in about $14 \%$ secondary to the peripheral fibers compression. In most cases, CN III palsy is limited to extrinsic oculomotricity secondary to central fibers ischemia, such as in diabetic patients. Diabetic ophthalmoparesia accounts for $25 \%$ of ocular motor nerve palsies and imaging is still normal in such cases of vasculopathic cranial neuropathy [19].

Painful lower CN disorders may also reveal dissection of the distal part of the vertebral artery or cervical portion of the internal carotid artery. Both CTA and MRA with nonenhanced FS T1 SE images are necessary.

\subsubsection{Arterio-Venous Fistula}

Carotido-cavernous fistulas can eventually cause raised intraocular pressure which can interfere with the blood supply of the optic nerve and can lead to blindness. These fistulas can best be detected on non-enhanced MRA. Abnormal high signal intensity can then be seen inside the cavernous sinus due to the increased speed of the venous flow caused by the fistula with the carotid. A congestive chemosis with a dilation of the superior ophthalmic vein is common.

\subsubsection{Neurovascular Compression Syndromes}

Neurovascular compression syndromes (NVCS) are usually caused by arteries or veins that directly compress and insult the cisternal portion of $\mathrm{CN}$ (Fig. 12.3). Common NVCS involve $\mathrm{CN}$ V with a trigeminal neuralgia $(\mathrm{V}), \mathrm{CN}$ VII with hemifacial spasm, CN VIII with vestibular paroxysmia (VIII), CN IX with glossopharyngeal neuralgia.

Indeed vessels in the posterior fossa elongate and become more tortuous with aging. Among all neurovascular contacts, few are symptomatic. While heavily T2-WI are very efficient in displaying nerve to vessel contact, the relationship with patient symptoms remains debated. In fact, one challenge is to determine which neurovascular contact could be symptomatic. The most common pathophysiological hypothesis relies on the natural weakness of $\mathrm{CN}$ in their transition zone, a short 1-2 $\mathrm{mm}$ segment in which the central myelin that originates from oligodendrocytes and covers the proximal intracisternal portion of $\mathrm{CN}$, turns into peripheral myelin from Schwann cells. Therefore, the correlation between clinical symptoms and the exact location of the neurovascular contact is crucial.
Trigeminal neuralgia (V) secondary to NVC is suspected when neural deformation by vascular contact is located approximately $4 \mathrm{~mm}$ from the apparent $\mathrm{CNV}$ origin from the brainstem, hemifacial spasm (VII) at $2 \mathrm{~mm}$, vestibular paroxysmia (VIII) at $10 \mathrm{~mm}$, and glossopharyngeal neuralgia at $<2 \mathrm{~mm}$ [20].

Venous conflicts are possible but most NVCS are caused by arteries, especially the superior cerebellar artery $(\mathrm{V})$, the anterior inferior cerebellar artery (VII, VIII), the posterior inferior cerebellar, and the vertebral artery (VII, VIII, IX).

Besides the exact location of the contact, reliable signs are a perpendicular neurovascular crossing and the displacement of the nerve. To confirm NVCS, nerves, arteries, and veins are distinguished using heavily T2-WI for nerves, unenhanced TOF MRA for arteries, and post-contrast 3D-submillimetric T1 WI for veins (Fig. 12.3).

Fusion software with selective color coding for each anatomical structure can be helpful, especially after decompressive surgery to recognize the position of the material (e.g., Teflon, etc.).

\subsubsection{Infectious Diseases}

\subsubsection{Viral Neuritis}

Bell's palsy accounts for a peripheral facial palsy secondary to herpes simplex virus related neuritis. Most patients recover spontaneously facial nerve function in $<2$ months without therapy. Imaging is usually performed in case of atypical clinical presentation, including persisting deficit and recurrence. Thin post-contrast FS T1-WI and 3D-FLAIR show a fundal "tuft" and labyrinthic facial nerve (VII) enhancement. Intrameatic and intralabyrinthic enhancements of the CN VII are always abnormal. Nodular enhancement may suggest differential diagnoses such a schwannoma, hemangioma, metastases, etc. Enhancement of the geniculate ganglion, tympanic, and mastoid segment of the nerve has to be interpreted with caution as these segments are surrounded by an arteriovenous plexus that may also enhance in normal subjects. To avoid this problem, it is recommended to use sequences that do not show the surrounding vessels enhancement like millimetric heavily T2-WI and post-contrast black blood 3DT1-WI (Fig. 12.3). Comparison with the contralateral side is useful to distinguish an excessive CN VII enhancement. Main differential diagnoses include facial nerve schwannoma, hemangioma, perineural tumor spread from parotid tumor, and Ramsay Hunt syndrome.

Ramsay Hunt syndrome accounts for a varicella zoster virus infection responsible of both sensory fibers of facial and cochleovestibular nerves. A facial palsy and a sensorineural hearing loss are associated with an external ear vesicular rash. Fever, vertigo, nausea, and burning pain of the ear are common. CN disorders may occur before the rash. Thus, MRI is helpful to identify a unilateral facial and cochleoves- 

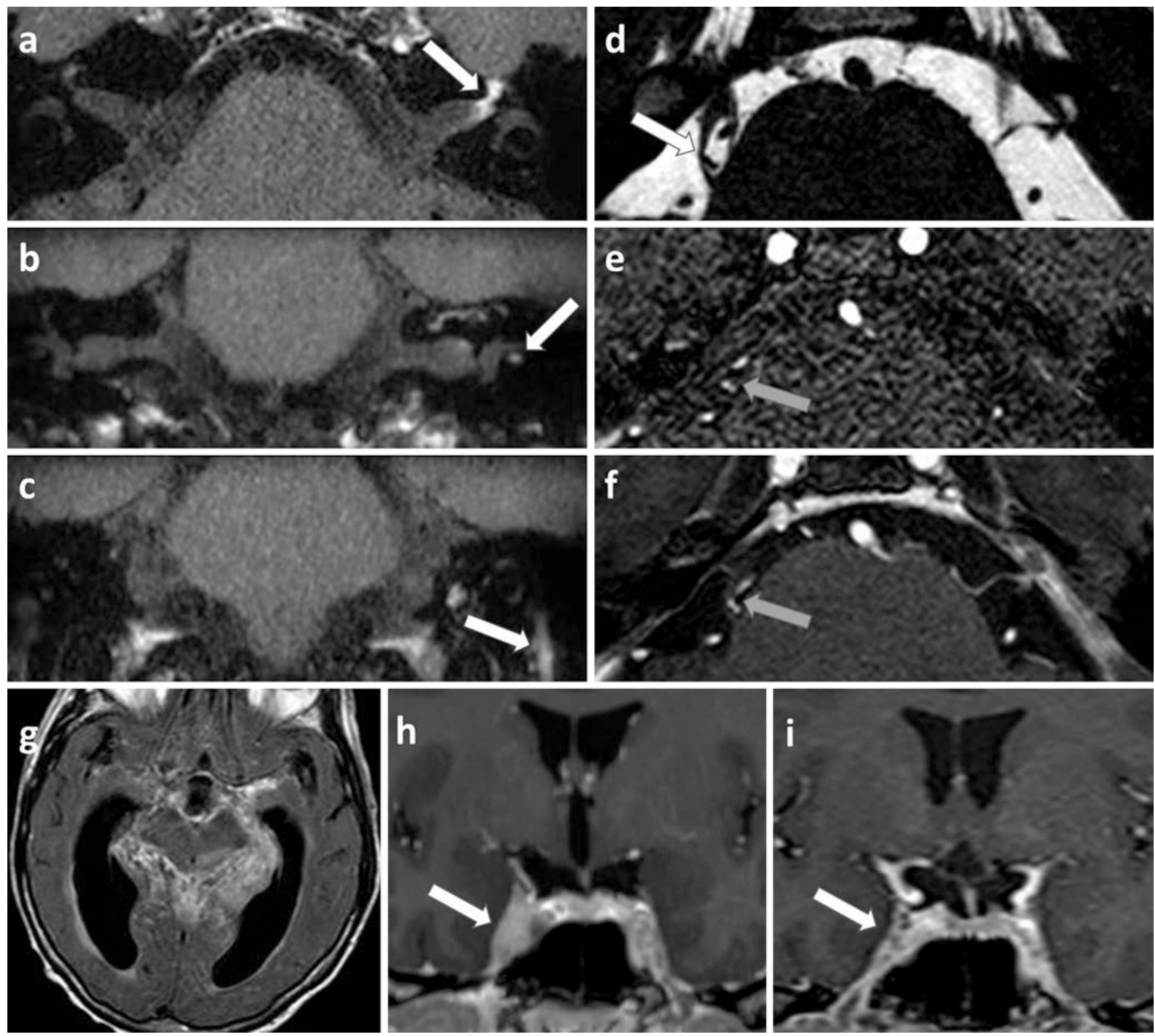

Fig. 12.3 Extraaxial intracranial lesions associated with $\mathrm{CN}$ disorders: $(\mathbf{a}-\mathbf{c})$ left Bell's palsy, a viral neuritis, axial $0.55 \mathrm{~mm}$ thick black blood 3D TSE T1-WI show unilateral left facial nerve enhancement in the fundus of the internal auditory canal and along the labyrinthine segment, and the geniculate ganglion (a arrow). Coronal reformatted images show an enhancement of the tympanic (b arrow) and mastoid segment (c arrow) of the left facial nerve. Note that these black blood images suppress both arterial and vein enhancement, making the diagnosis easier; (d-f) right trigeminal neuralgia in a neurovascular compression syndrome, axial $0.3 \mathrm{~mm}$ thick 3D TSE heavily T2-WI (d) shows the displacement of the transitional zone of the CN V by the right superior cerebellar artery (gray arrows) on TOF MRA (e) and postcontrast $0.5 \mathrm{~mm}$ thick 3D T1-WI (f); (g) tuberculous leptomeningitis, T2 FLAIR hyperintensities of the basal leptomeninges, revealed by bilateral oculomotor and facial palsies and headaches (hydrocephalus); (h, i) Tolosa-Hunt syndrome revealed by a painful right ophthalmoplegia, initial post-contrast T1-WI (e) show a right cavernous thickening without other potential diagnosis (white arrow), high-dose corticoid therapy amended symptoms and 6 months follow-up MRI (f) show normal cavernous sinus tibular enhancement into the fundus and the inner ear on thin post-contrast FS T1-WI and 3D-FLAIR. Additionally, heavily T2-WI shows a thickening of the nerves into the internal auditory canal and the inner ear. Comparison with the contralateral side is very helpful [21]. Other viruses such as HIV may also cause neuritis $[5,22]$.

\subsubsection{Infectious Meningitis}

$\mathrm{CN}$ disorders may reveal meningeal diseases. Indeed, a CSF study is often necessary to set the final diagnosis. In case of meningitis, $\mathrm{CN}$ disorders may consist in a non-specific abducens palsy (VI) to a multiple and bilateral CN palsies associated with a meningeal syndrome. 
Neuroimaging would demonstrate a meningeal enhancement of 3D post-contrast CT, T1, and Flair images. Leptomeningitis is characterized by an enhancement and a thickening of the leptomeninges contiguous to the CNS. Pachymeningitis is characterized by an enhancement and a thickening of the pachymeninges contiguous to the skull. Additional intraparenchymal lesions are common in case of diffuse meningeal diseases, suggestive of meningoencephalitis. Besides pyogenes meningitis, tuberculosis is a common bacterial cause of leptomeningitis involving the skull base and the brainstem (Fig. 12.3). This meningeal inflammation may cause a regional vasculitis and ischemic stroke.

\subsubsection{Skull Base Infections}

Multiple unilateral $\mathrm{CN}$ disorders are suggestive of skull base disease. In addition to clinical and biological data, CT and post-contrast MRI allow to identify symptomatic osteomyelitis usually secondary to naso-sinusal and otomastoid infections.

\subsubsection{Non Infectious Inflammatory Diseases}

\subsubsection{Non-infectious Meningitis}

Among non-infectious leptomeningitis, neurosarcoidosis is the most common cause of $\mathrm{CN}$ disorders. An additional diabetes insipidus is classical. Besides a diffuse leptomeningeal enhancement of post-contrast FS 3D-FLAIR and 3DT1-WI, MRI shows the loss of the bright spot of the posterior pituitary on non-enhanced T1 with thickened infundibulum and stalk.

Non-infectious pachymeningitis is a possible additional feature of granulomatosis and systemic diseases such as Wegener's disease, Langerhans cells, and non-Langerhans cells histiocytosis. Besides pachymeningeal thick enhancement and tumor-like appearance, a possible infundibular and stalk lesion responsible of diabetes insipidus, CT is useful to identify lytic lesions of the skull and the face.

\subsubsection{Tolosa-Hunt Syndrome}

Tolosa-Hunt syndrome is an idiopathic non-neoplastic noninfectious inflammation of the cavernous sinus and the orbital apex. A unilateral painful ophthalmoplegia usually reveals the disease. MR demonstrates an abnormal apical enhancement extended to the cavernous sinus and Meckel's cave that are enlarged with a lateral bulging. After having excluded infections and neoplasms on clinical, biological, and imaging presentation, high dose of steroids is required. Normal MRI at 6-months follow-up is required to set the final diagnosis [23] (Fig. 12.3).

Idiopathic inflammatory infiltration can also be detected in orbital pseudotumor as a T2 hypointense ill-defined infiltration which enhances on post-contrast FS T1-WI. Additional infiltration of the pituitary, infundibulum, lacrimal, and salivary glands is possible in case of IgG4-related disease. A thickening of infraorbitary nerve $\left(\mathrm{V}_{2}\right)$ would very suggestive [24].

\subsubsection{Tumors and Cysts}

\subsubsection{Neural Sheath Tumors}

Schwannoma is the most common neural tumor. This tumor that arises from the nerve sheath after the $\mathrm{TZ}$ may involve any $\mathrm{CN}$ but I and II that do not have Schwann cells. Most common $\mathrm{CN}$ are the vestibular nerve (VIII) within the cerebellopontine angle and the internal auditory meatus, the trigeminal nerve (V) in the Meckel's cave, the mixed nerves (IX, X, XII), and the hypoglossal nerve. The tumor is usually well-defined, homogeneously enhanced on post-contrast T1-WI. Cystic changes may occur in large schwannomas. Multiple schwannomas may occur. Indeed, bilateral vestibular schwannomas is specific of neurofibromatosis type 2 (Fig. 12.4).

In case of single neural mass, main differential diagnoses include facial hemangioma (VII), a small intrameatic heterogeneous lesion, and neuroma that may occur after focal insult [16-18]. Perineural spread of extracranial schwannomas may also extend into the skull.

In case of multiple neural tumors, main differential diagnoses include leptomeningeal metastases and carcinomatosis of extracranial solid tumors, leukemia, and lymphoma. Metastases of intraaxial primary neoplasms such as glioblastoma, medulloblastoma, ependymoma, germinoma are also possible. None of these metastases has a specific appearance. Appropriate diagnosis relies on patient's history, poor general condition, CSF study, and whole body imaging (Fig. 12.4)

\subsubsection{Meningeal Tumors}

Primary meningeal tumors such as meningioma are common. Unique or multiple in case of meningiomatosis, meningioma may displace and shear the $\mathrm{CN}$. Meningioma of the planum sphenoidale and the olfactory groove is a classical cause of anosmia (Fig. 12.4). In the cerebellopontine angle, meningioma is the main differential diagnosis of vestibular schwannoma. On CT, meningioma is often associated with hyperostosis, while schwannoma is responsible of a scalloping of the internal auditory meatus. Meningioma may extent anteriorly to the internal auditory meatus, while vestibular schwannoma usually does not. And perfusion imaging demonstrates the hypervascularization of the meningioma.

Intracranial meningiomas may extent throughout the skull base foramina, along the $\mathrm{CN}$ routes. The optic nerve is the nerve which is most frequently involved in its extracranial 

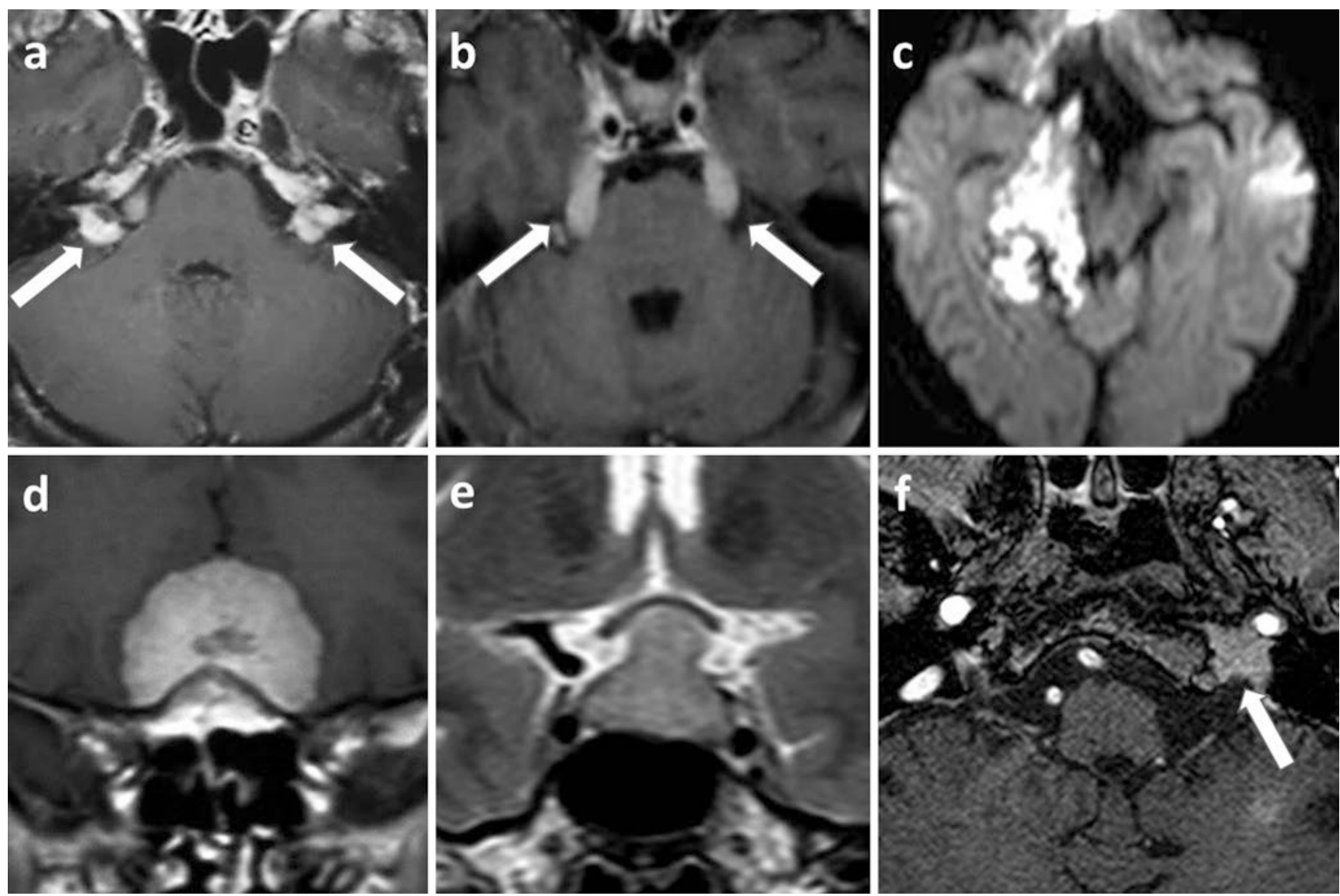

Fig. 12.4 (a) neurofibromatosis type 2, post-contrast T1 bilateral CPA and intrameatic masses, revealed by bilateral sensorineural hearing loss. (b) bilateral trigeminal metastases of leukemia appearing as postcontrast T1 bilateral trigeminal tumoral thickening. (c) epidermoid cyst along the right aspect of the midbrain, DWI hyperintense mass, revealed by right trochlear palsy. (d) meningioma of the cribriform plate, postcontrast $\mathrm{T} 1$ enhancing mass, revealed by anosmia. (e) pituitary mac- roadenoma, intra- and suprasellar mass, that shifts upwards the chiasma was revealed by bitemporal hemianopia. (f) paraganglioma of the left glomus jugular is a contrast-enhanced T1 mass infiltrating the jugular foramen with discrete "salt-and-pepper" appearance on post-contrast FS T1-WI (white arrow) revealed by motor palsies of the left lower nerves (IX-XII) course, followed by the mandibular nerve $\left(\mathrm{V}_{3}\right)$ and the lower cranial nerves IX-XI. Involvement of the later $\mathrm{CN}$ is seen as a mass in the carotid space which must be differentiated from a schwannoma or a paraganglioma. The strong enhancement, dural tail enhancement adjacent to the intracranial component of the meningioma and its iso-intensity with gray matter on all sequences help to recognize them.

Secondary leptomeningeal and pachymeningeal carcinomatosis of CNS tumors and extracranial solid tumors, leukemia, and lymphoma are better revealed on 3D post-contrast T1 and Flair images. Differential diagnosis with granulomatous meningitis can be difficult on imaging only.

\subsubsection{Skull Base Tumors and Tumor-like Lesions}

Multiple unilateral $\mathrm{CN}$ disorders are suggestive of skull base disease. In addition to clinical and biological data, CT and post-contrast MRI allow to identify symptomatic fibrous dysplasia, and bone tumors such as chordoma, chondrocarcinoma, or metastasis.

\subsubsection{Sellar Tumors and Cysts}

\section{Intrasellar and Perisellar Tumors}

Intrasellar and perisellar lesions may cause vision loss, especially bitemporal hemianopia due to chiasmatic compression (Fig. 12.4). Oculomotor disorders may occur in case of extension into the cavernous sinus. Most common lesions include pituitary macroadenoma and craniopharyngioma. The tumor is tissular and cystic-like, respectively. Both enhance on post-contrast images. A common Rathke cleft cyst should not be misdiagnosed.

\section{Rathke Cleft Cyst}

Rathke cleft cyst, a common incidental finding located within the pars intermedia of the pituitary or along the 
pituitary stalk, may rarely cause vision and oculomotor deficit. When symptomatic, the location of the cyst and the presence of small T2 hypointense nodules within the cyst are suggestive. The absence of peripheral and tissular enhancement allows to distinguish the cyst from craniopharyngioma.

\subsubsection{Pineal Tumors and Cysts}

Pineal tumors such as pinealocytoma and germinoma may cause a Parinaud syndrome, an oculomotor disorder associating up-gaze palsy, convergence-retraction nystagmus, and dilated pupils that react to accommodation but not to light. Additional non-specific symptoms are possible, including those related to obstructive hydrocephalus by compression of the aqueduct of the midbrain, and intracranial hypertension. Pineal tumors are suggested in case of nodular enhancement and tissular lesions, even when cystic component is present. Hypercellular germinomas may harbor hyperintense DWI due to restricted diffusion coefficient.

\section{Pineal Cyst}

Pineal cysts are common and usual non-symptomatic, their size is usually below $1 \mathrm{~cm}$. When larger, pineal cyst may cause a Parinaud syndrome and obstructive hydrocephalus that may require surgical CSF derivation in emergency. Pineal cyst contains CSF-like fluid. As protein concentration increases, T1 signal might increase and T2 signal decreases. A thin peripheral enhancement is possible while nodular and tissular enhancements suggest pineal tumors.

\subsubsection{Other Cysts and Cystic-like Lesions}

Cysts and cystic-like lesions are common findings around the $\mathrm{CNS}$ and $\mathrm{CN}$. These lesions are often incidental findings or may be revealed by $\mathrm{CN}$ disorders secondary to compression.

\section{Epidermoid Cyst}

Epidermoid cyst is related to the inclusion of ectodermal epithelial elements. It can be slow growing and revealed by $\mathrm{CN}$ disorders. The insinuating mass has well-defined borders. CT demonstrated a hypodense, similar to CSF. Marginal calcifications are possible. MR shows a CSF-like cyst that may change with protein concentration. The lesion does not enhance. Besides these features that may suggest an arachnoid cyst, a typical incidental finding in adults, MR demonstrates a typical restricted diffusion with hyperintense appearance (Fig. 12.4). Surgery consists in $\mathrm{CN}$ decompression.

\section{Neurenteric Cyst}

Neurenteric cyst is a congenital endodermal cyst that might arise in front of the medulla and the pons. $\mathrm{CN}$ disorders, such as abducens or mixed nerves palsies (VI), are possible. CT usually shows a prepontine lobular hyperdensity. MRI confirms a cyst with high proteins content as T2 hypointensity T1 spontaneous hyperintensity, no enhancement.

\section{Dermoid Cyst}

Dermoid cyst is well-circumscribed unilocular cyst arising from the midline, often close to the sellar and parasellar region. This squamous epithelial cyst contains dermal elements with fatty compounds from sebaceous secretion. Calcifications are common. Rupture of the cyst causes a chemical meningitis and hydrocephalus. CT and MR easily demonstrate the fat density of the cyst content with parietal calcifications. Rupture is suspected in case of diffuse fatty droplets scattered into the subarchnoïd spaces. Surgical treatment is discussed when symptomatic, such as $\mathrm{CN}$ disorders and rupture in association with CSF drainage.

\section{Lipoma}

Lipoma is a non-neoplastic mass of mature adipose tissue. Usually, lipomas do not grow over time and are incidental findings. However, lipomas might be diagnosed in case of $\mathrm{CN}$ disorders when located onto the quadrigeminal plate or into the cerebellopontine angle. CT demonstrates a homogenous low density mass ( -50 to $-100 \mathrm{HU})$ without calcification. MR demonstrates a hyperintense T1 mass which becomes hypointense after fat saturation. The lesion does not enhance. Surgical removal is difficult. When symptomatic, surgery consists in partial removal for $\mathrm{CN}$ decompression.

\subsubsection{Trauma}

Post-traumatic anosmia is usually due to contusion of olfactory bulbs or to olfactory fibers shearing through the cribriform plate that occur after occipital head trauma. High-resolution T2 WI may illustrate olfactory bulbs injuries. Beside this contrecoup anosmia, all other post-traumatic $\mathrm{CN}$ disorders are usually due to shearing or compression secondary to skull base fracture. Intraforaminal portions of $\mathrm{CN}$ are at risk of compression by surrounding hematoma or bone fragment displacement. Optic nerve contusion and shearing can also be observed.

Skull base fracture including petrous bone might be revealed by $\mathrm{CN}$ disorders. When clinically driven, highresolution $\mathrm{CT}$ is very sensitive to demonstrate to symptomatic fracture. MRI allows to depict adjacent edema and focal hemorrhage like in the internal ear. MRI and CTA may also demonstrate vascular injury such as arterial dissection and venous thrombosis.

Parenchymal herniations may also compress CN. Indeed, $\mathrm{CN}$ disorders may reveal slow growing lesion. Transtentorial herniation of the internal temporal gyrus might be revealed by oculomotor (III) and trochlear (IV) palsies. Transoccipital herniation of the cerebellar amygdala might be revealed by mixed nerves (IX-XI) and hypoglossal nerve palsies. 


\subsubsection{Degeneration}

\subsubsection{Superficial Siderosis}

Meningeal superficial siderosis may cause $\mathrm{CN}$ degeneration and disorders, especially sensorineural hearing loss. Chronic meningeal deposition of hemosiderin occurs in repeated trauma, subarachnoid hemorrhage, and slow growing tumor or in cerebral amyloid angiopathy. MRI demonstrated a characteristic hypointense rim coating the CNS and the $\mathrm{CN}$ on $\mathrm{T} 2 *$ and SWI.

\subsection{Extracranial Lesions}

Primary extracranial $\mathrm{CN}$ diseases are rare and include esthesioneuroblastoma of the olfactory nerves (I) and optic nerve (II) glioma, while schwannoma and neurofibroma may arise from all other nerves but CN VIII which has no extracranial segment.

Most extracranial $\mathrm{CN}$ disorders are secondary to a surrounding disease that may insult the nerves. Unilateral symptoms are most common.

Nasal and ethmoidal diseases may cause anosmia due to olfactory nerves (I) impairment.

Orbital diseases may cause partial or complete monocular visual loss (scotoma) because of optic nerve (I) involvement. Diplopia may be due to oculomotor (III), trochlear (IV), and abducens (VI) nerves dysfunctions. Intraorbital apical CN III lesion associates ptosis and mydriasis when the ciliary ganglion that receives afferent parasympathetic fibers is affected.

Superficial and deep facial lesions may cause trigeminal neuropathy when the extracranial branches of $\mathrm{CN} \mathrm{V}$ are injured. Specific signs may suggest particular branches, especially when unilateral: hypoesthesia, numbness, or burning of the forehead $\left(\mathrm{V}_{1}\right)$, the chick $\left(\mathrm{V}_{2}\right)$, the jaw $\left(\mathrm{V}_{3}\right.$. $)$; diminished or absent corneal reflex (ophthalmic branch $\mathrm{V}_{1}$ ); atrophic or weak muscles of mastication (motor branch $\mathrm{V}_{3}$ ). Facial pain is a very unspecific sign but numbness, progressive symptoms and motor weakness should always be taken seriously and are frequently linked to a structural lesion.

Perimastoid and parotid lesion may cause an extracranial CN VII dysfunction with isolated peripheral facial nerve palsy but preserved lacrimal function, stapedius reflex and taste in the anterior two thirds of the tongue.

In the suprahyoid region, CN IX to XII have close relationships explaining why they are often injured simultaneously. Association of CN IX and X disorder is frequent and result in otalgia, dysphagia, absent gag reflex, uvular deviation away from the side of the lesion, endolaryngeal symptoms (hoarseness, dysphagia in cervical esophagus, vocal cord palsy), loss of taste to the posterior $1 / 3$ of the tongue, tachycardia or bradycardia, etc. Isolated disorders of CN XI and XII are common. CN XI palsy is suggested on shoulder drop and inability to raise the arm. CN XII palsy is diagnosed on deviation of the tongue to the side of the lesion, amyotrophy of the intrinsic and extrinsic tongue muscles, and orobuccal dysarthria.

In the infra-hyoid region, lesions would result in an isolated $\mathrm{CN}$ X injury and vagus related oropharyngeal signs will be absent and only the endolaryngeal symptoms will be present. Muscle denervation atrophy is an indirect sign of involvement of the motor cranial nerves and should always be checked [25].

Besides the above mentioned lesions, neural disorders also occur in case of vasculitides, neurotoxin, after radiotherapy.

Because of the large spectrum of extracranial diseases, here are presented most common etiologies.

\subsubsection{Vascular Lesions}

Intraorbital cavernous hemangioma is an ovoid welldelineated enhancing lesion in the orbit and can compress the optic nerve (Fig. 12.5). Venous varix can be recognized on flow void, vascular enhancement, and size increase on procubitus.

Internal carotid artery dissection or (pseudo)aneurysm may cause deficits of the lower cranial nerves IX-XII, due to the compression on the nerves into the carotid space (Fig. 12.6). These nerves can also be damaged during endarterectomy.

Aneurysms of the aortic arch and even cardiomegaly can cause irritation of the left recurrent laryngeal nerve [26].

\subsubsection{Infectious Diseases}

Aggressive bacterial and fungal infections arising from sinuses, temporal bone, and skull base can insult the adjacent cranial nerves. Aspergillus and mucormycosis can be recognized on the very low signal inside the sinuses on T2-WI and the destruction of the bony walls of the sinuses.

All extracranial cranial nerves close to the sinuses and temporal bone can be affected by fungal infection and aggressive bacterial infection: frontal sinus $\left(\mathrm{V}_{1}\right)$, ethmoid and sphenoid (II, III, IV, $\mathrm{V}_{1}, \mathrm{~V}_{2}, \mathrm{VI}-$ orbital apex and superior orbital fissure), temporal bone (VII). Periapical and periodontal dental disease may cause maxillary $\left(\mathrm{V}_{2}\right)$ and mandibular $\left(\mathrm{V}_{3}\right)$ neuropathy which can be seen on postcontrast FS T1-WI or MR neurography [27].

The facial nerve can be involved in malignant otitis externa, a pseudomonas infection in diabetic or immunocompromised patients. Skull base osteomyelitis can also affect the lower cranial nerves IX-XII while mandibular 

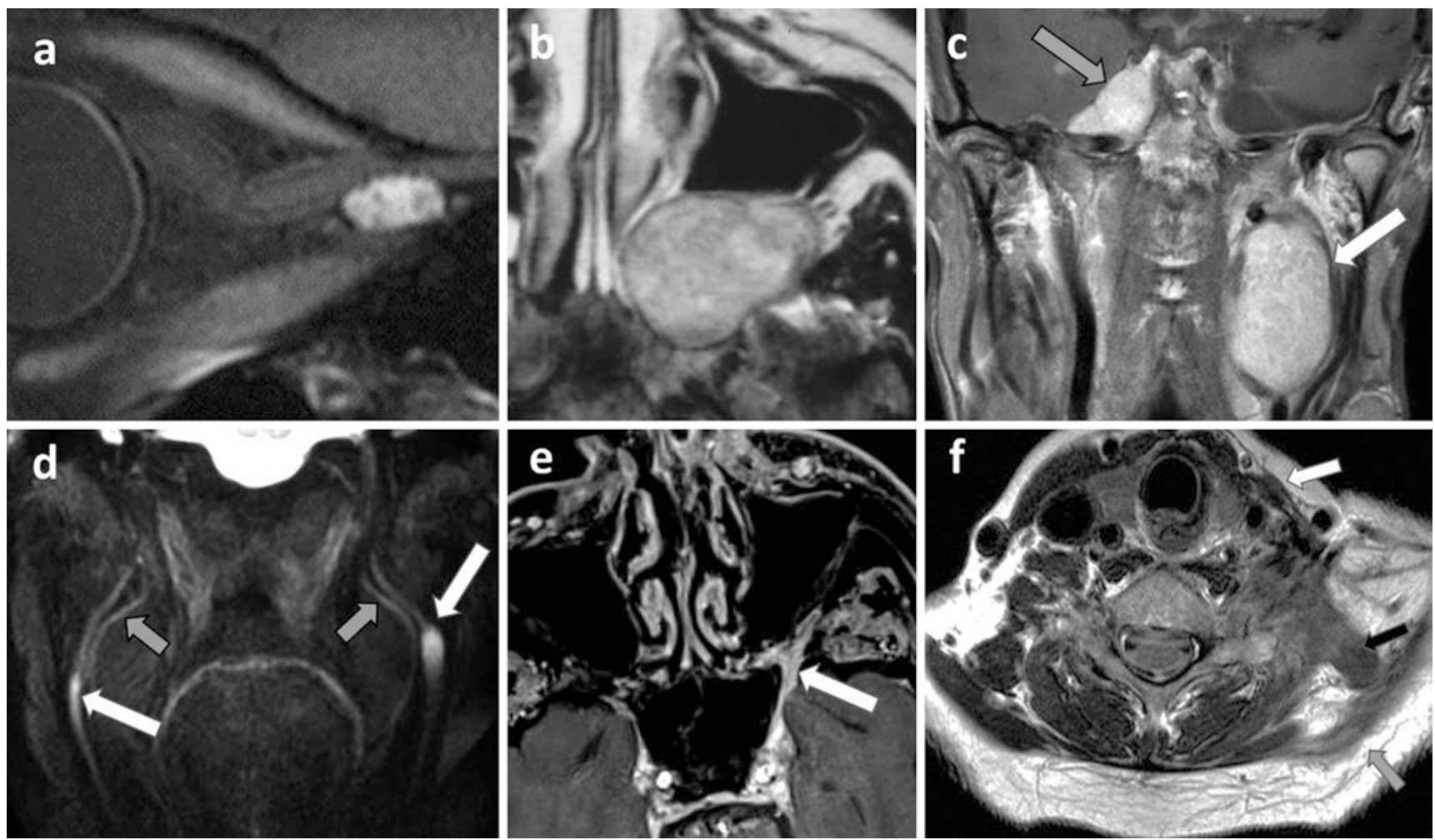

Fig. 12.5 (a) cavernous hemangioma of the orbital apex revealed by unilateral vision loss, the enhancement of the lesion and relation to the optic nerve is clear on this isotropic $0.55 \mathrm{~mm}$ thick post-contrast black blood 3D TSE T1-WI; (b) schwannoma of the left maxillary nerve $\left(\mathrm{V}_{2}\right)$ in the pterygopalatine fossa, as an expansive slightly heterogeneously enhanced on post-contrast T1-WI, scalloping the adjacent bones; (c) neurofibromatosis type 2 with multiple schwannomas of the left vagus nerve (X) (white arrow) and the right Meckel cave (gray arrow) on postcontrast coronal T1-WI; (d) neurofibromas on paracoronal 3D neurog-

raphy with black blood pulse as bilateral thickening and hyperintensity of both inferior alveolar nerves $\left(\mathrm{V}_{3}\right)$ (white arrows), external to lingual nerves (gray arrows). (e) Perineural tumor spread along the left maxillary nerve $\left(\mathrm{V}_{2}\right)$ of an epithelial carcinoma of the nostril (gray arrow), post-contrast FS T1 show a thickened enhancing $V_{2}$ in the pterygopalatine fossa, the rotundum foramen (white arrows); (f) post-traumatic left accessory nerve palsy (XI) with sternocleidomastoid (white arrow), trapezius muscles (gray arrow), and levator scapulae (black arrow) muscles degeneration

osteomyelitis can cause inferior alveolar nerve irritation with pain and numbness. This mandibular osteomyelitis should be differentiated from osteoradionecrosis. Both will result in loss of the high signal inside the mandible and both can enhance. However, osteoradionecrosis can be distinguished when bone sequesters are present, hypointense defects are seen in the cortex and when periosteal bone is formed.

Abscess formation in the carotid space can cause lower cranial nerve IX-XII symptoms and mediastinitis and mediastinal inflammatory adenopathy can cause left sided CN X or recurrent laryngeal nerve deficits.

\subsubsection{Non-infectious Inflammatory Diseases}

\subsubsection{Demyelinating Diseases}

In young adults, spontaneous vision loss is often due to an optic neuritis, which can be a particular feature of demyelin- ating diseases such as multiple sclerosis (MS) and neuromyelitis optica spectrum disorders (NMOsd) with anti-AQP4 or anti-MOG antibodies. Accurate diagnosis assessment is needed because of different treatments with potential deleterious effects when inappropriate. Besides clinical and biological data, whole CNS imaging that includes optic nerves is mandatory. Optic nerve lesions are best identified using post-contrast FS T1-WI and 3D-FLAIR.

In MS, optic neuritis is usually unilateral, short, involving the middle portion of the nerve.

In anti-AQP4+, optic neuritis is usually bilateral, long, involving the posterior portion of the nerves with chiasmatic extension.

In anti-MOG+, optic neuritis is usually bilateral, long, involving the anterior portion of the nerves.

Additional CNS imaging abnormalities are helpful for differential diagnosis.

In MS, MRI demonstrates scattered nodules in the brain and the upper half of spinal cord. Spinal lesions are small 

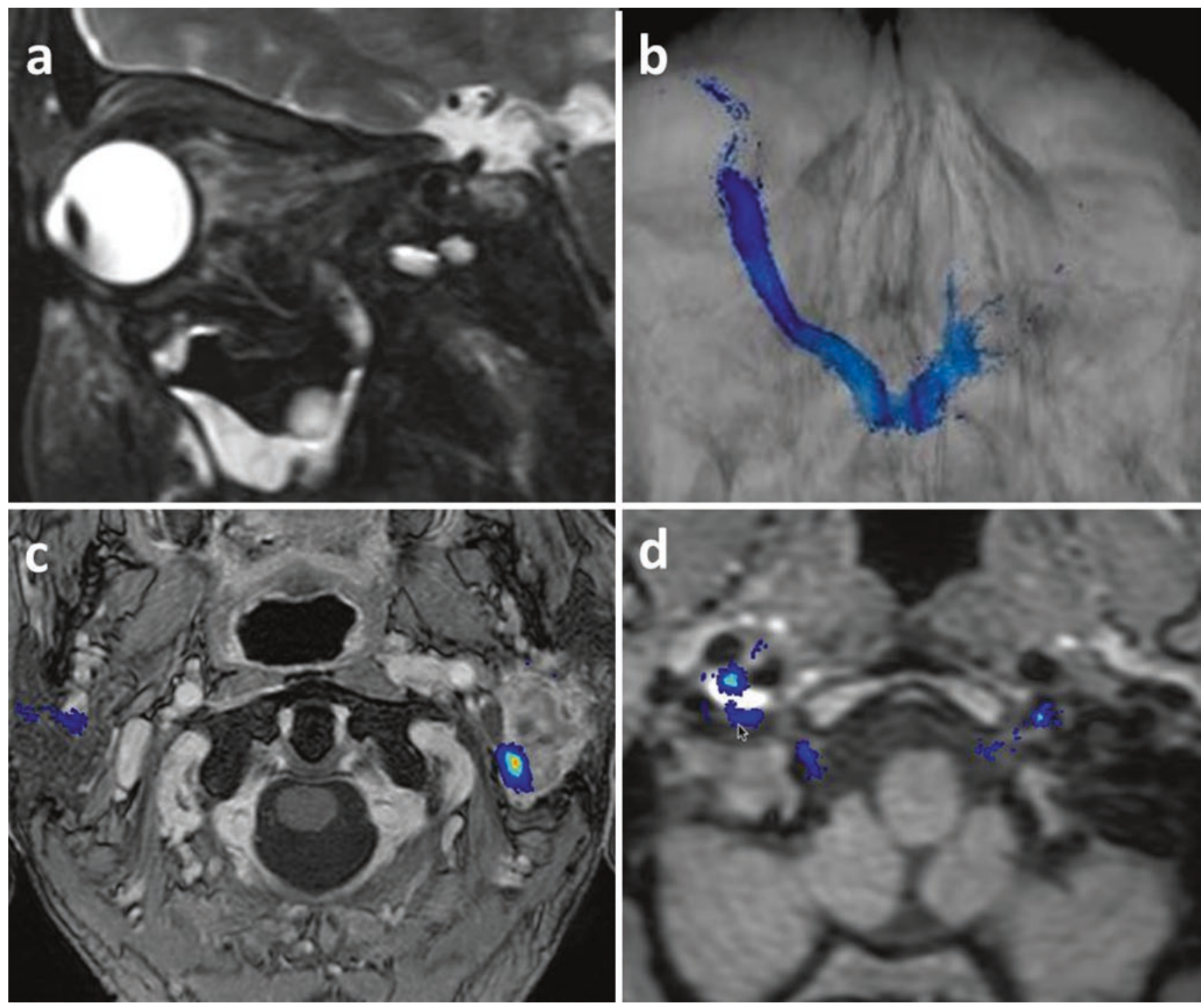

Fig. 12.6 (a, b) post-traumatic left vision loss, sagittal FS T2 (a) shows a retrobulbar edema and an optic nerve hyperintense contusion, optic nerve probabilistic tractography suggests a nerve section of poorer prognosis; (c) facial nerves tractography showing the left posterior dis-

extending over $<2$ vertebral segments on sagittal images, and occupying $<50 \%$ of the cord diameter of axial images. Dissemination in time accounts for plaques of varied contrast uptake.

In anti-AQP4+, brain lesions are mostly periventricular with a suggestive involvement of the area postrema. Spinal cord lesions are usually located in the upper half of the cord, involving three or more vertebral segments on sagittal images, more than $50 \%$ of the cord diameter.

In anti-MOG+, brain lesions are involving more often basal ganglia, thalamus, and the pons. Spinal cord lesions are usually located in the lower half of the cord, involving three or more vertebral segments on sagittal images, more than $50 \%$ of the cord diameter $[14,15]$. placement of the nerve by a parotid cystadenolymphoma; (d) hypoglossal nerves tractography showing the contact with the right internal carotid dissection in a patient referred for a painful hypoglossal palsy

\subsubsection{Granulomatous Diseases}

Extracranial lesions of various granulomatous diseases, such as Wegener's disease, Langerhans cells and non-Langerhans cells histiocystosis, can insult the anterior optic pathways in association with orbital and naso-sinusal lesions. Involvement of the adjacent orbit can occur with potential optic nerve and/ or maxillary nerve involvement. Intracranial extension following the neural routes is possible.

Optic nerves and anterior optic pathways can be affected in $1-5 \%$ of sarcoidosis patients. Sarcoidosis is an inflammatory granulomatosis that can mimic optic nerve meningioma. In these patients careful examination of the systemic signs should lead to the diagnosis. However, bilateral optic nerve involvement, enhancement of the complete optic nerve from 
the globe to the chiasm, bilateral enlargement of lacrimal and parotid glands, leptomeningitis, and infundibular thickening are imaging signs indicative of sarcoidosis $[1,2,5,7]$.

\subsubsection{Orbital Pseudotumor}

Orbital pseudotumor is a benign non-infectious inflammatory condition of the orbit. As a diagnosis of exclusion, systemic causes such as infections and neoplasms should be ruled out. Patients present with sudden painful proptosis, ophthalmoplegia (III, IV, VI), vision loss (II), uveitis and retinal detachment. An ill-defined enhancing pseudo-mass involving any area of the orbit is best detected on postcontrast FS T1-WI. A very fast response to corticosteroid treatment is necessary to confirm the diagnosis.

\subsubsection{Grave's Ophtalmopathy}

Graves' disease is an autoimmune disease affecting the thyroid and Graves' ophtalmopathy is found in more than $25 \%$ of the patients. Extraocular muscle hypertrophy and adipogenesis cause increased ocular pressure and proptosis, possible diplopia (extraocular muscle involvement) and vision loss (II).

\subsubsection{Tumors}

\subsubsection{Primary Nerve Lesions}

\section{Esthesioneuroblastoma}

Esthesioneuroblastoma or olfactory neuroblastoma is a rare tumor arising from the olfactory neurosensory receptor cells in the olfactory epithelium of the high nasal vault. Nasal obstruction, rhinorrhea, epistaxis, anosmia, headaches are common. CT and MRI show a dumbbell tissular mass, enhanced on post-contrast images with peripheral cysts. Bone destruction allows spreading into the ethmoid and the sphenoid sinuses, through the cribriform plate and the anterior cranial fossa.

\section{Optic Nerve Glioma}

As the optic nerve is an extension of the brain, primary tumor is an optic nerve glioma, usually a pilocytic astrocytoma. This glioma occurs under the age of 20 years. The typical appearance is a fusiform lesion on the optic nerve with T2 hyperintensity and a variable enhancement. It causes a kinking of the optic nerve and the lesion may reach the optic chiasm. Optic nerve glioma can be associated with neurofibromatosis type I (NF1), especially when bilateral. NF1associated optic tumors rarely extend beyond the optic pathway and are usually not cyst-like, whereas those not associated with NF1 usually involve the optic chiasm, extend extra-optically, and are frequently cyst-like [28].

\subsubsection{Nerve Sheath Tumors}

As extracranial extension of CNS, intraorbital optic nerves are surrounded by CSF and meningeal sheath. Optic nerve sheath meningioma appears as a fusiform mass surrounding the optic nerve. Post-contrast T1-WI demonstrates a perineural homogeneous enhancement with a "tram track" appearance. CT may show linear calcifications. CSF may be trapped between the tumor and the eyeball.

Optic nerves and olfactory tracts and bulbs have no Schwann cells. However, the olfactory filia which are connecting the olfactory mucosa with the olfactory bulbs do have Schwann cells and hence "olfactory schwannomas" are reported although they do not originate on the olfactory nerve itself.

All other $\mathrm{CN}$ but VIII have an extracranial course with Schwann cells on which nerve sheath tumors can arise, including schwannomas, neurofibromas, and rarely malignant tumors.

They are less often found on the short orbital apex segment of CN III, IV, and VI. The chance to find such tumors on the end branches of the trigeminal nerve (V) is higher (Fig. 12.5) but far less frequent than on its intracranial portion.

Nerve sheath tumors along intraparotid branches of $\mathrm{CN}$ VII do occur but one is most frequently dealing with extensions of a mastoid segment lesion into the parotid gland.

Nerve sheath tumors can be detected on all four lower cranial nerves but schwannomas of $\mathrm{CN} \mathrm{X}$ are most frequent. Extracranial schwannomas of CN XII frequently pass through the hypoglossal canal into subarachnoid space. Extracranial schwannomas of CN IX and XI are rare.

Schwannomas are well-circumscribed, fusiform in shape and have intense enhancement (Fig. 12.5). Cystic, fatty, and hemorrhagic degeneration are possible. Schwannomas are solitary and sporadic in most cases in old adults. However, autosomic dominant neurofibromatosis type 2 (NF2) is likely when multiple schwannomas are present, and bilateral vestibular schwannomas are pathognomonic. In case of hereditary NF2, patients are younger. And the tumoral onset occurs at a younger age than the affected parent.

Schwannomas might be difficult to distinguish them from neurofibromas, discovered at about 20-30 years. Neurofibromas appear as a mild to non-enhancing thickening of a longer segment of the nerve (Fig. 12.5). Similarly, most neurofibromas are solitary and sporadic. However multiple neurofibromas and plexiform neurofibromas almost assure the diagnosis of NF1.

\subsubsection{Secondary Nerve Involvement}

\section{Head and Neck Malignancies}

Squamous cell carcinomas, adenoid cystic carcinomas, adenocarcinomas, lymphomas, melanomas arising in the face, 
sinus, orbit, supra- and infra-hyoid neck can all cause displacement of or invasion of the extracranial $\mathrm{CN}$.

The causative tumors can be different in more specific areas like uveal melanoma and retinoblastoma for the optic nerve, esthesioneuroblastoma for the olfactory bulbs and ophthalmic nerve $\left(\mathrm{V}_{1}\right)$, rhabdomyosarcoma $\left(\mathrm{V}_{3}\right)$, malignant parotid gland tumors such as adenoid cystic carcinoma and mucoepidermoid carcinoma for the facial nerve (VII) and bronchogenic carcinoma and thyroid malignancies for the infra-hyoid vagus nerve (recurrent laryngeal nerve) (X).

Tumoral infiltration of extracranial nerves could be difficult to see but the presence of a tumor at the $\mathrm{CN}$ endpoint or along its extracranial route allows to make the diagnosis. Post-contrast FS T1-WI are helpful to follow thickened enhanced CN. Diffusion tractography is promising for clinical practice, showing nerve displacement and suggesting tumoral infiltration [11] (Fig. 12.6).

It should not be forgotten that the left recurrent laryngeal nerve, branch of the vagus nerve $(\mathrm{X})$, passes through the aortopulmonary window and can therefore be affected by mediastinal adenopathies and malignancies of the aerodigestive tract.

\section{Perineural Tumor Spread}

Adenoid cystic carcinoma, squamous cell carcinoma and lymphoma are the most frequent malignant head and neck lesions with perineural spread, although other malignant tumors also have the potential to follow the cranial nerves [29]. The most frequently involved nerves are the $V_{1}$ (skin and lacrimal malignancies), $\mathrm{V}_{2}$ (skin, oral and nasal cavity and sinus malignancies) (Fig. 12.5), $\mathrm{V}_{3}$ (oral cavity-sublingual and submandibular gland and masticator space malignancies) [30], VII (parotid malignancies), and rarely the CN XII.

The perineural spread can be seen as an abnormal enhancement and thickening of the nerve on post-contrast FS T1-WI (Fig. 12.5). Comparison with the contralateral nerve facilitates the diagnosis. It is crucial to detect intracranial $\mathrm{CN}$ extension as it diminished therapeutic options and result in a poorer prognosis.

CN V and VII have several connections, often involved in perineural tumor spread, which allow tumoral spread along both nerves and their branches. Involvement of the connection between the maxillary nerve $\left(\mathrm{V}_{2}\right)$ and vidian nerve (VII) at the level of the pterygopalatine fossa is the most frequently involved connection. Hence, the pterygopalatine fossa should always be checked in detail as its involvement often heralds intracranial extension along the above mentioned branches.

\section{Paragangliomas}

Paragangliomas are vascular tumors arising from glomus bodies located along carotid bulb and the vagus nerve in the carotid space, the jugular foramen, and the middle ear cavity. They are easy to recognize on MRA as the typical fast blood flow in the arterial feeders can be recognized on these images, setting the final diagnosis. A "salt-andpepper" appearance on post-contrast T1-WI is also classical (Fig. 12.4). These lesions can cause compression on any of the four lower $\mathrm{CN}$ into the carotid space. It is important to detect possible intracranial extension for surgical planning.

\section{Metastases}

Hematogenous metastases from malignant breast, kidney, lung, melanoma, prostate tumors to the head and neck region can involve all extracranial nerves with secondary $\mathrm{CN}$ disorders.

In the orbit, metastases from breast carcinomas are most frequent and compression on the nerve by orbital metastases is far more frequent than direct metastasis to the optic nerve itself.

Other CN III-XII can all be directly involved by the above mentioned metastases or indirectly by metastatic lymph nodes. CN involvement is best seen on post-contrast FS T1-WI in both axial and coronal planes.

\subsubsection{Trauma}

In addition to skull base fractures that threaten foraminal segment of $\mathrm{CN}$, facial bones fractures may also insult extracranial segment of CN (Fig. 12.6).

Branches of the trigeminal nerve (V) are at risk of injury, especially in case of: orbital roof and superior orbital fissure fracture $\left(\mathrm{V}_{1}\right)$; orbital floor and inferior orbital fissure fracture $\left(\mathrm{V}_{2}\right)$, mandible (collum and between the mandibular and the mental foramina) and central skull base fractures $\left(\mathrm{V}_{3}\right)$.

Optic canal fracture threatens $\mathrm{CN}$ II and orbital apex fracture CN III, IV, VI.

$\mathrm{CT}$ is needed to identify fractures and bone fragments displacement which damage $\mathrm{CN}$. $\mathrm{CN}$ contusions or shears are best seen on MR inversion recovery images through the nerves. Post-traumatic neuropathy can be recognized as thickened hyperintense nerves on MR neurography [8].

$\mathrm{CN}$ disorders may also be iatrogenic after sinonasal and periorbital surgery (II, III, IV, VI), tooth implant and mandibular surgery $\left(\mathrm{V}_{3}\right)$, parotid surgery (VII), etc. Neck dissections can result in lower $\mathrm{CN}$ deficits (Fig. 12.5) and surgery in the lower neck can even damage the recurrent laryngeal nerve causing vocal cord palsy. The postsurgical scar formation replaces the fat around the nerves on T1-WI and can enhance in the early postsurgical period. 


\subsection{Conclusion}

Cranial nerves disorders are frequent and reveal a broad variety of diseases. Imaging investigation has to be conducted in agreement with the medical history and presentation. Imaging $\mathrm{CN}$ coverage has to be discussed from nucleus to target. CT and CTA are useful to rule out symptomatic aneurysm and dissection and to better identify skull lesions and calcifications. MRI remains the best imaging modality for $\mathrm{CN}$, and diffusion tractography can illustrate $\mathrm{CN}$ structural changes.

\section{Take Home Messages}

- Master anatomy and function to fully explore $\mathrm{CN}$ from nucleus to target

- Rule out intracranial lesions that require specific treatment.

- Rule out aneurysm and dissection when painful CN disorder using CTA and MRA

- MRI relies on thin slices and 3D, including heavily T2-WI, FLAIR, T1, fat saturation, pre- and postcontrast. Consider optional DWI/DTI and SWI.

Acknowledgments We acknowledge the help of Dr. Arnaud Attyé and Dr. Timothée Jacquesson.

\section{References}

1. Barkhof F, Jäger R, Thurnher M, Rovira A, editors. Clinical neuroradiology: the ESNR textbook. Cham: Springer; 2019. 2272 pp.

2. Casselman J, Mermuys K, Delanote J, Ghekiere J, Coenegrachts K. MRI of the cranial nerves--more than meets the eye: technical considerations and advanced anatomy. Neuroimaging Clin N Am. 2008;18:197-231, preceding $\mathrm{x}$.

3. Chapman $\mathrm{P}$, Harnsberger $\mathrm{H}$, Vattoth $\mathrm{S}$, editors. Imaging anatomy: head and neck. Philadelphia: Elsevier; 2019. 700 pp.

4. Harnsberger H. Cranial nerves. In: Harnsberger H, Osborn A, Macdonald A, Ross J, editors. Diagnostic and surgical imaging anatomy: brain, head and neck, spine. Salt Lake City: Amirsys; 2006. p. 174-259.

5. Koch B, Hamilton B, Hudgins P, Harnsberger H, editors. Diagnostic imaging: head and neck. 3rd ed. Philadelphia: Elsevier; 2017. $1352 \mathrm{pp}$

6. Leblanc A, editor. Encephalo-peripheral nervous system: vascularisation, anatomy, imaging. Berlin: Springer; 2004. 420 pp.

7. Osborn A, Hedlund G, Salzman K, editors. Osborn's brain. 2nd ed. Philadelphia: Elsevier; 2018. 1300 pp.

8. Romano N, Federici M, Castaldi A. Imaging of cranial nerves: a pictorial overview. Insights Imaging. 2019;10:33.
9. Jacquesson T, Cotton F, Attye A, Zaouche S, Tringali S, Bosc J, Robinson P, Jouanneau E, Frindel C. Probabilistic Tractography to predict the position of cranial nerves displaced by skull base tumors: value for surgical strategy through a case series of 62 patients. Neurosurgery. 2019;85:E125-36.

10. Attye A, Jean C, Remond P, et al. Track-weighted imaging for neuroretina: evaluations in healthy volunteers and ischemic optic neuropathy. J Magn Reson Imaging. 2018;48:737.

11. Rouchy RC, Attye A, Medici M, Renard F, Kastler A, Grand S, Tropres I, Righini CA, Krainik A. Facial nerve tractography: a new tool for the detection of perineural spread in parotid cancers. Eur Radiol. 2018;28:3861-71.

12. Attye A, Karkas A, Tropres I, et al. Parotid gland tumours: MR tractography to assess contact with the facial nerve. Eur Radiol. 2016;26:2233-41.

13. van der Zijden T, Mondelaers A, Yperzeele L, Voormolen M, Parizel P. Current concepts in imaging and endovascular treatment of acute ischemic stroke: implications for the clinician. Insights Imaging. 2019;10:64.

14. Dutra BG, Jose da Rocha A, Nunes RH, Martins Maia Junior AC. Neuromyelitis optica spectrum disorders: spectrum of MR imaging findings and their differential diagnosis-erratum. Radiographics. 2018;38:662.

15. Dutra BG, da Rocha AJ, Nunes RH, Maia ACMJ. Neuromyelitis optica spectrum disorders: spectrum of MR imaging findings and their differential diagnosis. Radiographics. 2018;38:169-93.

16. Bonneville F, Savatovsky J, Chiras J. Imaging of cerebellopontine angle lesions: an update. Part 2: intra-axial lesions, skull base lesions that may invade the CPA region, and non-enhancing extraaxial lesions. Eur Radiol. 2007;17:2908-20.

17. Bonneville F, Savatovsky J, Chiras J. Imaging of cerebellopontine angle lesions: an update. Part 1: enhancing extra-axial lesions. Eur Radiol. 2007; 17:2472-82.

18. Krainik A, Cyna-Gorse F, Bouccara D, Cazals-Hatem D, Vilgrain V, Denys A, Rey A, Sterkers O, Menu Y. MRI of unusual lesions in the internal auditory canal. Neuroradiology. 2001;43:52-7.

19. Adams ME, Linn J, Yousry I. Pathology of the ocular motor nerves III, IV, and VI. Neuroimaging Clin N Am. 2008;18:261-82, preceding $\mathrm{X}-\mathrm{x}$.

20. Haller S, Etienne L, Kovari E, Varoquaux AD, Urbach H, Becker M. Imaging of neurovascular compression syndromes: trigeminal neuralgia, hemifacial spasm, vestibular Paroxysmia, and glossopharyngeal neuralgia. AJNR Am J Neuroradiol. 2016; 37:1384-92.

21. Kuya J, Kuya K, Shinohara Y, Kunimoto Y, Yazama H, Ogawa T, Takeuchi $\mathrm{H}$. Usefulness of high-resolution 3D multi-sequences for peripheral facial palsy: differentiation between Bell's palsy and Ramsay hunt syndrome. Otol Neurotol. 2017;38:1523-7.

22. Veillon F, Taboada LR, Eid MA, Riehm S, Debry C, Schultz P, Charpiot A. Pathology of the facial nerve. Neuroimaging Clin N Am. 2008;18:309-20, x.

23. Zurawski J, Akhondi H. Tolosa-hunt syndrome--a rare cause of headache and ophthalmoplegia. Lancet. 2013;382:912.

24. Soussan JB, Deschamps R, Sadik JC, et al. Infraorbital nerve involvement on magnetic resonance imaging in European patients with IgG4-related ophthalmic disease: a specific sign. Eur Radiol. 2017;27:1335-43.

25. Smoker WR, Reede DL. Denervation atrophy of motor cranial nerves. Neuroimaging Clin N Am. 2008;18:387-411, xi. 
26. Lee JH, Cheng KL, Choi YJ, Baek JH. High-resolution imaging of neural anatomy and pathology of the neck. Korean J Radiol. 2017;18:180-93.

27. Chhabra A, Bajaj G, Wadhwa V, Quadri RS, White J, Myers LL, Amirlak B, Zuniga JR. MR neurographic evaluation of facial and neck pain: normal and abnormal craniospinal nerves below the skull base. Radiographics. 2018;38:1498-513.
28. Louis D, Ohgaki H, Wiestier O, Cavenee W, editors. WHO classification of tumors of the central nervous System. 4th ed. Lyon: IARC; 2016.

29. Maroldi R, Farina D, Borghesi A, Marconi A, Gatti E. Perineural tumor spread. Neuroimaging Clin N Am. 2008;18:413-29, xi.

30. Borges A, Casselman J. Imaging the trigeminal nerve. Eur J Radiol. 2010;74:323-40.

Open Access This chapter is licensed under the terms of the Creative Commons Attribution 4.0 International License (http://creativecommons. org/licenses/by/4.0/), which permits use, sharing, adaptation, distribution and reproduction in any medium or format, as long as you give appropriate credit to the original author(s) and the source, provide a link to the Creative Commons license and indicate if changes were made.

The images or other third party material in this chapter are included in the chapter's Creative Commons license, unless indicated otherwise in a credit line to the material. If material is not included in the chapter's Creative Commons license and your intended use is not permitted by statutory regulation or exceeds the permitted use, you will need to obtain permission directly from the copyright holder. 